\title{
Employer Branding in Creating of an Organization's Image - Example of SME's
}

\author{
Aneta PACHURA ${ }^{1}$, Małgorzata SMOLAREK ${ }^{2}$ \\ ${ }^{1}$ Czestochowa University of Technology, Częstochowa, Poland \\ aneta.pachura@wz.pcz.pl \\ ${ }^{2}$ University of Social Science, Kraków, Poland \\ msmolarekesan.edu.pl
}

\begin{abstract}
The paper's theoretical and empirical considerations were focused on the process of organization's image creating. The purpose of the research was to analyze the possibilities of using employer branding to create the image of an organization in a business environment. The theoretical basis of the organization's image and the employer branding issue are presented. Interpretation of the image was based on a simplified analysis of selected cognitive perspectives. In this paper, attention was paid, among others to competitive advantage, perception in the business environment, the brand and the identity of the organization. The phenomenon of the employer branding was explained by referring to the organization's value creating, human resource management, relational marketing, etc. Then the results of the empirical quantitative research were presented. Questionnaire surveys were aimed at recognizing selected tools of employer branding in creating the image of an attractive employer. The results confirmed the interest of SME's in using such employer branding tools as: social media, website, job fairs, and open days.
\end{abstract}

Keywords: Organization Image, Employer Branding, Employer Branding Tools.

\section{Introduction}

Striving to enhance their internal systems, enterprises increasingly focus their attention on actions aimed at improving their position in business environment. The current business environment is becoming ever more dynamic and difficult to predict. The ability to navigate through the space of social networking determines an organisation's success. Investing in the development of social potential by recruiting highly-qualified employees, implementing training systems to improve staff qualifications or creating a friendly environment in the organisation is becoming a common practice among enterprises.

It seems that today's labour market of highly developed countries requires strategic activities from enterprises to attract the most valuable employees. This can naturally be seen as connected with such phenomena as digitalisation of business processes or automation and robotisation. In this context, employees who create values for the organisation in the most productive way are its key resource. Thus, the ability to „attract" the most valuable employees to an organisation is regarded as a very significant factor in building the competitive advantage and using new business models in practice. This shows how important it is for an organisation to create an image that 
confirms its attractiveness as a potential employer. It is worth highlighting that the basics of the concept of employer branding can be used to consciously remodel an organisation's image for the purpose of the labour market.

\section{The Goal of the Research and Methodology}

The goal of the research presented in this paper is to examine the possibilities of using the employer branding concept to create the image of an organization. The research was based on theoretical and empirical studies. Exploration of selected tools of employer branding in the context of shaping an organisation's image was one of the stages of the research programme entitled ,Trends and challenges in strategic management of SMS's in the Silesian Province" (the project was carried out between November and December 2016 among a group of small and medium-sized enterprises in the Silesian Province). Recruitment processes were analysed to identify key tools of employer branding. The aim of the research was to identify the factors determining interest in an enterprise as a potential employer. An organisation's image was accepted as the basic research perspective and viewed as an attribute that allows an enterprise to stand out against others in the labour market and facilitates processes of recruiting employees with high qualifications. The research hypothesis was formulated as follows: Conscious use of selected tools of employer branding makes it possible to shape an organisation's image that is desirable from the perspective of the labour market.

Table 1. Characteristics of the research sample

\begin{tabular}{|c|c|c|}
\hline \multicolumn{3}{|c|}{ Total research sample $=320(100 \%)$} \\
\hline \multicolumn{3}{|c|}{ Characteristics describing the respondents of the survey } \\
\hline \multirow[t]{2}{*}{ gender of the respondents } & females & $42.0 \%$ \\
\hline & males & $58.0 \%$ \\
\hline \multirow{5}{*}{$\begin{array}{c}\text { age of the respondents (in } \\
\text { years) }\end{array}$} & do 29 & $15.1 \%$ \\
\hline & $30-39$ & $29.2 \%$ \\
\hline & $40-49$ & $46.7 \%$ \\
\hline & $50-59$ & $6.6 \%$ \\
\hline & over 60 & $2.4 \%$ \\
\hline \multirow{3}{*}{$\begin{array}{l}\text { education of the } \\
\text { respondents }\end{array}$} & higher & $43.4 \%$ \\
\hline & secondary & $44.8 \%$ \\
\hline & vocational & $11.8 \%$ \\
\hline \multicolumn{3}{|c|}{ Characteristics describing the enterprises participating in the survey } \\
\hline \multirow{4}{*}{$\begin{array}{c}\text { when the enterprise was } \\
\text { established }\end{array}$} & $\ldots-1989 \mathrm{r}$ & $12.3 \%$ \\
\hline & $1990-2000$ & $48.6 \%$ \\
\hline & $2001-2010$ & $28.8 \%$ \\
\hline & $2011-\ldots$ & $10.4 \%$ \\
\hline \multirow{2}{*}{$\begin{array}{l}\text { scale of the enterprise's } \\
\text { activity (market) }\end{array}$} & domestic & $45.8 \%$ \\
\hline & local & $17.5 \%$ \\
\hline
\end{tabular}




\begin{tabular}{clc}
\hline & regional & $30.7 \%$ \\
\cline { 2 - 3 } & international & $6.1 \%$ \\
\hline \multirow{2}{*}{$\begin{array}{c}\text { size of the enterprise, } \\
\text { according to the number of } \begin{array}{c}\text { microenterprise (0-9) } \\
\text { employees }\end{array}\end{array}$} & $\begin{array}{c}\text { small enterprise (10-49) } \\
\text { medium-sized enterprise }\end{array}$ & \begin{tabular}{c} 
(50- \\
\cline { 2 - 3 }
\end{tabular} \\
\cline { 2 - 3 } & $249)$ & $6.6 \%$ \\
\hline
\end{tabular}

The empirical research was quantitative in character. By using a survey questionnaire as a research tool, the responses, which represented subjective opinions of the survey's respondents, could be presented as percentages. The research sample was 320 respondents. Detailed characteristics describing the research sample are presented in table 1.

\section{Interpretation of Organization Image - Overview of Selected Cognitive Perspectives}

In management studies, discussions on the topic of an organisation's image in accordance with Porter's classical approach are conducted in the context of generic strategies for competitive advantage. It is recognised that the issue of image creation may become an element of creating differential advantage $[5,16]$. General interpretation of an organisation's image identifies the way of perceiving an enterprise in business environment [13, p. 127]. Perception means in this sense a certain established image of an organisation. It is agreed that "the corporate image is the perception that any audience has of an organization through the accumulation of received messages" [12, p. 21]. Thus, if a certain set of information about a specific organisation shapes its image in business environment, then the answer to the question: How to consciously create and manage information to successfully create the desired image of an enterprise? becomes key. This question is not groundless, especially from the perspective of the development of social relations in the network space and intensification of information flows.

It is based on information that opinions about organisations are shaped. In this sense, corporate image is defined as a „set of opinions, thoughts and impressions, which one creates about a firm or a product. Attitudes and acts of humans have connection with image of the firm or product" [9, p. 262].

When addressing the subject of corporate image, attention is also directed, apart from information, opinions, thoughts, impressions, attitudes and behavior of humans, to the organisation itself, which is perceived in terms of an entity functioning in business environment. Thus, corporate image is directly connected with the process of perceiving an organisation as an entity that exists autonomously or is associated with the creations of the organisation. This cognitive context suggests that image always involves something that exists beyond an organisation, is created in the minds or consciousness of external observers. In this sense, ,when a customer regards your company as a good community player, honourable employee, an innovator or added value creator, then your outgrowth is trusted, you have achieved a successive level of image" $[6, p .3]$. 
An attempt to identify the essence of corporate image leads to distinction of two essential cognitive perspectives. The first perspective suggests that image should be examined by viewing it in terms of the nature of an enterprise's brand. The second one, in turn, explains image in the context of an organisation's identity. In both cases, the areas of interests mainly include the scale of cohesion of both the concepts, their distinctiveness, dependencies existing between them and identified differences.

Based on general interpretation of image and brand, both these concepts are inseparably intertwined. However, one can find a view in the literature that brand is a much more important and stronger attribute of an organisation compared to corporate image. It is stressed that ,image can never be more important than the brand. But the brand may be nothing without its image - and can never be divorced from it" [14, p. 117].

An enterprise's organisational environment drives, in a sense, the search for characteristics showing the distinction between the concepts of image and identity. There is a discussion in the literature that leads to identification of significant differences between these concepts. Interpretations of both these concepts usually raise the issue of an illegitimate identification of image with identity. It is strongly emphasised that „the corporate identity is the visual representation of the company and should not be confused with the corporate image" [13, p.127]. In this case, the separateness of both these concepts has to do with the dimension of visualisation of an enterprise in business environment. The visual representation usually means: corporate signature, corporate symbol or an enterprise's logo [13, p. 127]. Meanwhile, the search of separateness on a semantic level leads to indication of corporate identity and corporate image [4, pp. 292-315]. When studying semantic differences between these meanings in the context of a substantial generalisation, it can be assumed that corporate identity is a sort of an organization's ,self-image“.

\section{$4 \quad$ Idea of Employer Branding}

The context of interpreting image as a certain perception of an organisation in business environment [13, p. 127] drives the search for ways to create the desired image of an enterprise. Moreover, the dynamic character of image, which is subject to changes, gives rise to the need to identify desirable image-building activities. This creates space for using the attributes of employer branding.

When attempting to define the idea of employer branding, one should start with definitions of brand. In this case, brand becomes a link, as it were, that binds the issues of shaping corporate image and development of employer branding. Indeed, when looking for interpretation of the term ,image”, one can also find references in the literature pointing to its connections with brand [14, p. 117]. However, in the description of employer branding, the context of brand enters the sphere of an organisation value creation and management of human resources. Thus, brand is essentially regarded as one of key values of every enterprise. It is most often associated with such factors as: organisation's name, product and/or service, graphical sign or logo of a product. However, if brand is viewed as an attribute that shapes interest of potential candidates for employees, then it can be regarded as an important part of Human Resource Management, HRM. Thus, the prospect of attracting highly specialised 
employees to an organisation strengthens the role of brand in effective management of human resources [10, pp. 19-26].

The context of recruiting highly specialised employees shapes the idea of employer branding. Discussion on this subject appeared in the academic literature already in the 1990s, as empirical research into this field intensified $[1,8]$. However, as more and more scientific reports on employer branding were appearing, one work became of key importance in that period of emerging of this research concept: The Employer Brand (by T. Ambler and S. Barrow) published in 1996. Employer brand was defined as ,the package of functional, economic and psychological benefits provided by employment, and identified with the employing company" [3, p. 187]. The starting point for the emergence and development of this concept is regarded to be the assumptions of relational marketing [7, 15] and the widely accepted concept of Human Resource Management.

The perspective of offering benefits on functional, economic and psychological levels requires a detailed exploration of possibilities of applying the principles of employer branding. It turns out that the key issue is not the package of benefits alone, but above all preservation of the continuity of image building activities. The literature stresses that ,a clear understanding and practical application of employer branding principles, based on establishing, maintaining and positioning of the unique attractive image of the company as an employer in the labour market enables the company to operate successfully in terms of the so-called war for talents" [11, p. 136]. One can thus gather that there is a need to shape the desired image in business environment by engaging in continuous image-building activities. Moreover, these activities should be thought-out and consistent with the assumptions of the strategy for human resources management. Thus, undertaking image-building activities requires not only coherence and consistence, but also employment of specific tools for positioning the organisation's image in the network.

The description of employer branding provided in the literature confirms that the development of this phenomenon is a typical example of interpenetration of theoretical concepts present in scientific research and the ever-more widespread corporate practice. The empirical approach indicates a number of limitations to studies of employer branding. Especially if one considers the process of seeing, perceiving and analysing the reality. In general terms, brand is something elusive. It is noted that ,brand concerns image, reputation, and identity: sometimes it is a fact, but it is always a perception" [2, p. 153]. Moreover, there is no clear evidence that an enterprise's strategy regarding employer brand is necessary for it to have the status of an attractive employer. However, one can assume that a conscious application of the principles of employer branding may support the process of building the desired image of an organisation, strengthening its position in the labour market. 


\section{Employer Branding in the Practice of SME's - Perspective of Recruitment of Employees}

\subsection{Presentation of the Results of Quantitative Research}

The respondents participating in the survey expressly indicated that the opinion about the employer and prestige of working in a given organisation are the key factors determining their decisions to take up employment (fig. 1). The vast majority (over $80 \%$ of those surveyed) viewed the opinion about the employer as relevant. According to over half of those surveyed $(56.6 \%)$, the prestige of being employed in a given organisation is a very important factor in considering its offer as interesting. Of importance is also the possibility of professional development $(49.1 \%$ of the respondents). The standard instruments of financial and non-financial motivation were only recognised by slightly over $20 \%$ of those surveyed $(28.8 \%$ and $22,5 \%$ respectively).

Analysis of selected factors that determine employment confirms that the image of an organisation as a potential employer is becoming increasingly important in the recruitment process. However, it is worth stressing that small and medium-sized enterprises, despite problems with acquiring highly qualified employees, are still paying little attention to image-building activities. Only $19 \%$ of those surveyed $(19.1 \%$ to be exact) notice image-building activities carried out in the organisational environment of the companies in which they are currently employed. Worryingly, over $80 \%$ of those surveyed ( $80.9 \%$ to be exact) claim that their company does not engage in any activities aimed at image building.

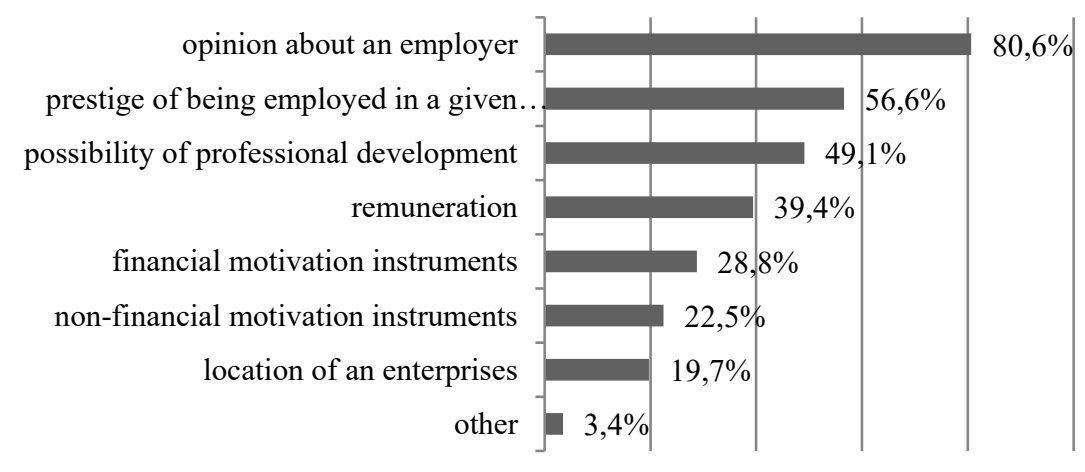

Fig. 1. Selected factors determining employment in an enterprise - SME sector.

It is worth stressing that corporate image-building activities are most often undertaken together with marketing activity and human resource management. In the organisational environment of the enterprises surveyed, in the vast majority of cases, marketing and HR departments were engaged in image-building activities (fig. 2). Over $67 \%$ of the respondents indicated involvement of marketing department employees, and almost $30 \%$ of those surveyed recognized the involvement of HR department $(67.2 \%$ and $29.5 \%$ respectively). Only $3.3 \%$ of the respondents, which accounts for only $0.9 \%$ 
of the research sample, could identify a dedicated department in the organisational environment of enterprises that engage in image-building activities.

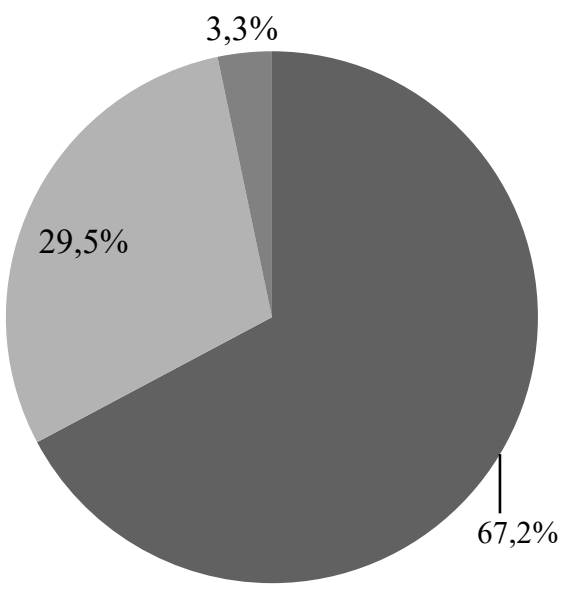

- marketing department

- HR department

- dedicated department responsible for imagebuilding activities

Fig. 2. Enterprises' internal organisational units involved in image-building activities - SME sector.

When exploring employer branding tools in the context of a conscious creation of corporate image, one should emphasize particular importance of social media. According to the overwhelming majority of those surveyed, social media and the career section/webpage are among the most common tools employed to enhance image in small and medium-sized enterprises. The contribution of social media was indicated by as many as $77 \%$ of those surveyed (fig. 3). The respondents expressed significant interest in the use of the career section/webpage. This tool is a kind of a „business card” of an organisation that is a potential employer, and thereby it aids the recruitment process.

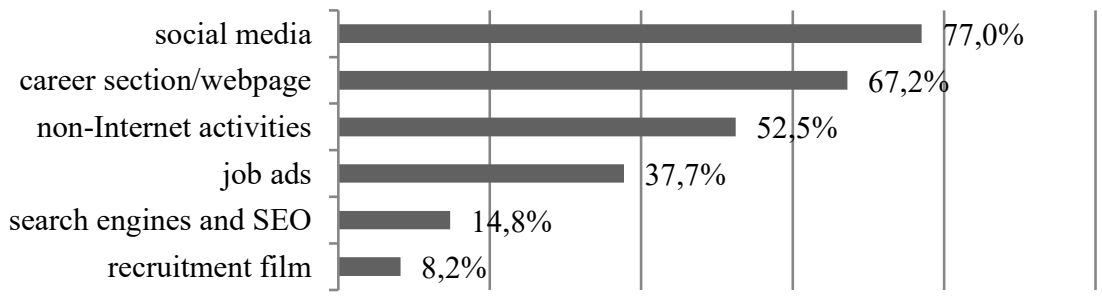

Fig. 3. Selected tools of employer branding in SME's. 


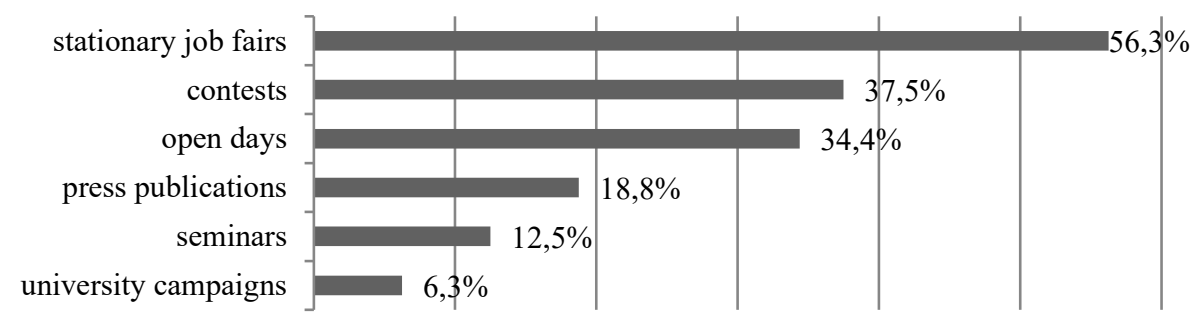

Fig. 4. Non-Internet tools of employer branding in SME sector.

The survey results show that the most underrated tools of employer branding include: job ads and search engines and SEO (Search Engine Optimization) (fig. 3). According to those surveyed, job ads have the greatest impact $(37.7 \%$ of the respondents). Almost $15 \%$ of the respondents indicated the use of search engines and SEO (14.8\%). A recruitment film was regarded as the least useful tool $(8.2 \%$ of those surveyed). Over half of the respondents $(52.5 \%)$ indicated non-Internet activities aimed at building corporate image (fig 3). A detailed look at such activities shows that offline job fairs are a key, non-Internet tool of employer branding (fig. 4). It is followed by organisation of competitions and open days (37.5\% and $34.4 \%$ respectively). In the context of image-building activities, seminars and meetings at universities are the least commonly used tools among enterprises.

\subsection{Results of the Empirical Research}

There is a widespread view that activities aimed at creating corporate image identify an organisation's position in the external environment, including in the labour market. The „status" of an organisation improves its image as an attractive employer, becoming an ever-more important factor determining interest among potential employees. Of importance is also a recruitment process, during which particular attention should be paid to such aspects as: manner and tools of communication with the candidate, assessment of competencies, and the quality of feedback. The experience of small and medium-sized enterprises confirms that the context of creating corporate image and the improvement of recruitment processes increasingly involve the use of employer branding tools. The quantitative research conducted among small and medium-sized enterprises indicates the following:

- frequent use of social media for creation of corporate image,

- reliance on the career section/webpage when searching for information about an organisation and recruitment rules,

- insufficient promotion of job ads through search engines and recruitment films,

- engagement in non-Internet activities aimed at creating corporate image.

It is a fact that social media, both professional (such as Goldenline, LikedIn) and mass (i.e. Facebook, Twitter) are actively used to create the desired image of an organisation. It seems, however, that real benefits in this respect can only be achieved by those organisations whose internal organisational system is open and flexible. Indeed, system 
openness and flexibility enable relations to be created, used and maintained. Thereby, they are a condition of an open discussion with Internet users.

The respondents participating in the survey expressed great interest in the use of the career section/webpage. This tool is treated mainly as a platform used to obtain up-todate and reliable information. Thus, of importance is the „form" of this section/webpage, including especially:

- attractiveness of the webpage/section,

- appearance that attracts attention and wins users' trust,

- reliability, up-to-date character and manner of presenting the information,

- employed visualisation tools.

Analysis of another tool of employer branding shows that search engines are minimally used to promote job offers. Small and medium-sized enterprises still do not recognise the potential of search engines (e.g. Google) and take insufficient actions in the area of SEO. It seems that such activities would allow a job offer to reach the target group of specialists. Similarly, an interesting recruitment film could act as an effective tool not only in a recruitment campaign but also in a promotional campaign of an enterprise.

When creating their corporate image in the external environment, small and mediumsized enterprises also focus on non-Internet tools of employer branding. Given the need to integrate business and academic environments, it seems very surprising that such image-building activities as seminars or meetings organised at universities are not widely used. Corporate image is mainly created through organisations' activity at job fairs. Thus, one can gather that classical forms of making potential candidates for work interested in job offers prevail. Exchange of information and experiences during seminars and meetings organised at universities is still unrecognised.

\section{Conclusion}

The results of the empirical research were used to draw conclusions about creation of corporate image in face of the need to stand out against the external environment and improve recruitment processes in order to ensure a successful recruitment of highly competent employees. Referring to the research hypothesis formulated in this paper, one can postulate the possibility of using employer branding tools for shaping the image of an organisation that is desired from the perspective of the labour market.

In the business environment, corporate image is an important attribute of an organisation. Not only in the context of the possibility of achieving a business position that is important in terms of cooperation or the creation, use and maintenance of network relations. It turns out that corporate image determines interest among potential candidates for employees, especially those highly qualified. It is a condition for success, as it were, of the recruitment process, forming the basis for developing an organisation's social potential. It is worth highlighting the need to improve the properties of social potential, especially such as knowledge, skills and social competences.

The empirical research conducted on the sample of 320 respondents clearly shows that small and medium-sized enterprises in the Silesian Province are by far insufficiently interested in engaging in image-building activities. The group of 
enterprises that do engage in image-building activities apply employer branding tools. Particular usefulness is attributed in this respect to such tools as social media, the career section/webpage and non-Internet activities (i.e. off-line job fairs, competitions and open days).

However, the use of employer branding tools for shaping corporate image that is desired from the perspective of the labour market is not limited to activities aimed at attracting new employees. It is worth emphasising strongly that the use of employer branding should not stop when a potential candidate for an employee becomes interested in the job offer, is ,attracted” and finally employed in an organisation. It seems necessary to invest in the already possessed social potential to increase employees' satisfaction and involvement. Such approach may constitute a basis for building an image of a reliable and attractive employer.

It is also worth noting that the present intensification of migration processes also should be reflected in the image-related strategy of modern enterprises. It seems important at this point to pay attention to such issues as multiculturalism, diversity or virtuality. Image-building activities should thus involve the sphere of creating a desired image of an enterprise to the outside world and that of creating a friendly internal organisational environment. In this context, an attractive employer is one that shapes the internal organisational environment based on such principles as respect of values, acceptance of otherness, acceptance of changeability and uncertainty. It also recognises the need to constantly improve the organisation by remoulding the concepts of business to adjust them to the current conditions. Relating the issue of creating corporate image to the character of migration processes may be a very interesting perspective for further empirical research.

\section{References}

1. Aaker, D.A.: Managing Brand Equity: Capitalizing on the Value of a Brand Name. Free Press, New York (1991).

2. Aldousari, A., Robertson, A., Zafar, M., Ahmed, U.: Impact of Employer Branding on Organization's Performance. Journal of transnational management, 22(3), 153-170 (2017). DOI: 10.1080/15475778.2017.1335125.

3. Ambler, T., Barrow, S.: The Employer Brand. Journal of brand management, 4, 185-206 (1996).

4. Christensen, L., Askegaard, S.: Corporate Identity and Corporate Image Revisited - A Semiotic Perspective. European journal of marketing, 35(3/4), 292-315 (2001).

5. Doyle, P., Stern, P.: Marketing Management and Strategy. Fourth edition. Pearson Education Limited, Harlow (2006).

6. Gregory, J.R., Wiechman, J.G.: Marketing Corporate Image. Business Books, Chicago (1999).

7. Gronroos, Ch.: Relationship Marketing Approach to Marketing in Service Contexts: The Marketing and Organizational Behavior Interface. Journal of business research, 20(January), 3-11 (1990).

8. Kosnik, T.J.: Designing and Building a Corporate Reputation. Design management journal, Winter, 10-16 (1991).

9. Kotler, P.: Principles of Marketing. Fourth European edition. Pearson Education Limited, Harlow (2005). 
10. Kunerth, B., Mosley, R.: Applying Employer Brand Management to Employee Engagement. Strategic HR review, 10(3), 19-26 (2011).

11. Mokina, S.: Place and Role of Employer Brand in The Structure of Corporate Brand. Economics \& sociology, 7(2), 136-148 (2014).

12. Nicolas, I.: Corporate Image. Strategies for Effective Identity Programs. Kogan Page, London (1992).

13. Obasan, K.: Organizational Culture and Its Corporate Image: A Model Juxtaposition. Business and management research, 1(1), 121- 132 (2012).

14. Ogilvy, D.: On Advertising. Prion Books, London (2001).

15. Sheth, J., Parvatiyar, A.: Relationship Marketing in Consumer Markets: Antecedents and Consequences. Journal of the Academy of Marketing Science, Fall, 255-271 (1995).

16. Smith, P., Taylor, J.: Marketing Communications. An Integrated Approach. Kogan Page, London and Philadelphia (2006). 